Results Twelve of 17 patients with BD showed findings of intestinal involvement in enteroclysis (70.58\%). Disease duration and duration of intestinal involvement were 3-19 years (median 8.09 years) and 1 month- 8 years (median 3.02 years) respectively. The findings were aphtous ulceration $(\mathrm{n}=10)$, linear ulceration $(\mathrm{n}=4)$, deep ulceration $(\mathrm{n}=1)$, coarse granular pattern $(\mathrm{n}=$ $1)$, thickened folds $(\mathrm{n}=5)$, wall thickening $(\mathrm{n}=2)$, pseudopolypoid appereance of the ileocecal valve $(n=6)$, long segment involvement $(\mathrm{n}=1)$, perforation and reccurrence at the side of anastomosis after right hemicolectomy $(\mathrm{n}=1)$. In 50 Crohn?s cases, disease duration were 3 months-22 years (median 4.14 years). Ten cases were in the early,11 in the intermediate and 29 in the advanced radiological stage with or without complication. Conclusion

- Enteroclysis is the method of choice with a high accuracy rate $(70.58 \%)$ for symptomatic patients to detect the intestinal pathology in BD.

- The enteroclysis findings in BD even when longstanding were usually mild when compared to those seen in CD. The main finding in BD was superficial ulceration. Deep ulceration common in $\mathrm{CD}$ was seen in only one patient with $\mathrm{BD}$.

\section{SAT0198 HOW NORMAL ARE THE HANDS OF NORMAL CONTROLS? A STUDY WITH DEDICATED MAGNETIC RESONANCE IMAGING}

${ }^{1} \mathrm{M}$ Parodi, ${ }^{2} \mathrm{G}$ Dazzi, ${ }^{2} \mathrm{E}$ Silvestri, ${ }^{2} \mathrm{G}$ Garlaschi, ${ }^{2} \mathrm{E}$ Poggi, ${ }^{1} \mathrm{MA}$ Cimmino. ${ }^{1} \mathrm{Clinica}$ Reumatologica, Dipartimento Di Medicina Interna, Università Di Genova, Genova; ${ }^{2}$ Dipartimento Di Medicina Sperimentale, Università Di Genova, Genova, Italy

\subsection{6/annrheumdis-2001.696}

Background Imaging of the joints is an invaluable technique for rheumatoid arthritis (RA). Magnetic resonance imaging (MRI) is increasingly used to visualise joint lesions in RA. ${ }^{1}$ MRI is a very sensitive technique, which is able to show subtle changes of the joints. However, little is known about MRI findings in normal subjects.

Objectives Our study evaluated bone lesions, articular space and thickness of the synovial membrane in normal controls.

Methods 50 hands of 25 controls (19 women) with age range 31-88 years were studied. Four subjects had slight osteoarthritis of the first carpometacarpal joint: this joint was excluded from further evaluation. MRI of the hand was performed using a 0.2T dedicated device (Artoscan, Esaote, Genova, Italy). GE T1 and STIR sequences were used on the coronal and axial planes. Evaluated lesions included a) bone oedema; b) erosions; c) tenosynovitis, and $d$ ) thickness of the synovial membrane and effusion in 6 different areas of the wrist, as well as in the MCP and PIP joints.

Results Bone oedema was seen in one subject only. Bone erosions were seen in 9/25 controls (36\%). They were more frequent in subjects older than 65 years (50\% vs. $23 \%$; ns). The localization of erosions in the normal hand was not different from that observed in RA. Tenosynovitis of the extensor and flexor tendons was seen in 2/25 (8\%) and 4/25 (16\%) of controls, respectively. It was more frequent in subjects older than 65 years $(41.7 \%$ vs. $7.7 \% ; p=0.07)$. Erosions and tenosynovitis were not associated with manual labour. Joint space range was calculated in 14 different locations of the hand. No differences were found according to gender. In contrast, subjects aged more than 65 years showed an increased thickness of the synovial membrane at the radio-ulnar joint $(\mathrm{p}=0.01)$ and in the intercarpal row $(\mathrm{p}=0.002)$, and an increased joint space in the third ( $\mathrm{p}=0.03)$ and fifth $(\mathrm{p}=0.04) \mathrm{MCP}$ joints.

Conclusion Bone erosions and tenosynovitis are frequent findings in normal subjects. In contrast, bone oedema was seen in only one control and seems therefore to be a specific finding of arthritic joints. Age, but not sex or manual activity, was associated with these changes. Articular space in the MCP and PIP joints, and synovial membrane thickness in 6 different locations of the wrist were increased in elderly subject. Our results indicate that caution should be used in defining MRI changes as specific for arthritis and in interpreting the data of published studies. Sufficiently large control groups should be included in studies of the arthritic joints.

\section{REFERENCE}

1 Cimmino, et al. Semin Arthritis Rheum. 2000;30:180-95

\section{SAT0199 AORTIC AORTIC ROOT FUNCTION IN PATIENTS WITH RHEUMATOID ARTHRITIS: EVALUATION BY S WITH RHEUMATOID ARTHRITIS: EVALUATION BY}

${ }^{1} \mathrm{D}$ Evcik, ${ }^{2} \mathrm{M}$ Alpaslan, ${ }^{2} \mathrm{E}$ Onrat. ${ }^{1}$ Physical Medicine and Rehabilitation; ${ }^{2}$ Cardiology, Kocatepe University, Afyon, Türkiye

\subsection{6/annrheumdis-2001.697}

Background Aortic Root Function in Patients with Rheumatoid Arthritis: Evaluation by M-Mode Echocardiography.

Objectives To evaluate aortic root function in patients with rheumatoid arthritis.

Methods 29 patients with rheumatoid arthritis (RA) (mean age 51 years) and 29 healthy subjects (mean age 49 years) participated in the study. In addition to the standard echocardiographic examination, aortic root function was evaluated in these groups by transthoracic M-mode echocardiography. RA was diagnosed according to the ARA criteria of 1987. Blood pressure with endsystolic (AoS) and end-diastolic (AoD) M-mode measurements of ascending aorta were used to calculate the indices of aortic root function: beta index (Peterson's elastic modulus), cross-sectional aortic compliance, aortic stiffness index and aortic root distensibility. The mean values of the two groups were compared by covariance analysis, taking age as the covariant. A p value $<0.05$ was assumed to be significant.

Results AoS and AoD were significantly higher in patients with RA than the control group $(\mathrm{p}<0.05)$. Aortic stiffness and beta indexes were significantly higher in RA group when compared with the controls.

Conclusion When compared with the controls AoS, AoD, beta index and aortic stiffness index are significantly higher in patients with RA. This may affect cardiac function in patients with RA at long term.

\section{REFERENCES}

1 Leibowitz WB. The heart in rheumatoid arthritis (rheumatoid disease). A clinical and pathological study of 62 cases. Ann Intern Med. 1963;58:102-23

2 Gravallese E, Corson J, Coblyn JS, et al. Rheumatoid arthritis: a rarely recognized but clinically significant entity. Medicine 1989;68:95-106

3 Urschel CW, Covell JW, Sonnenblick EH, Ross J, Braunwald E. Effects of decreased aortic compliance on performance of the left ventricle. Am J Physiol. 1968:214:298-304

4 Kelly RP, Tunin R, Kass DA. Effect of reduced aortic compliance on cardiac efficiency and contractile function of in situ canine left ventricle. Circ Res. 1992;71:490-502 